\title{
Lysyl Oxidase Mechanisms to Mediate Gastrointestinal Cancer Progression
}

\author{
Ahmadshah Farhat ${ }^{a}$ Gordon A. Ferns ${ }^{b}$ Korosh Ashrafic \\ Mohammad-Hassan Arjmand ${ }^{c, d}$
}

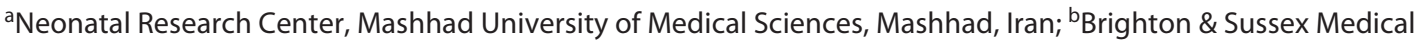

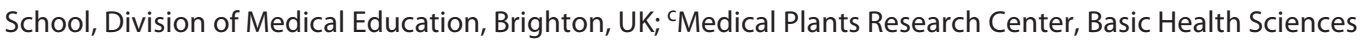
Institute, Shahrekord University of Medical Sciences, Shahrekord, Iran; ${ }^{d}$ Cancer Research Center, Shahrekord University of Medical Sciences, Shahrekord, Iran

\author{
Keywords \\ Lysyl oxidase - Extracellular matrix stiffness . \\ Gastrointestinal malignancies · Angiogenesis . \\ Inflammation
}

\begin{abstract}
Background: Malignancy is a complex process resulting from different changes such as extracellular matrix (ECM) remodeling and stiffness. One of the important enzymes that contribute to ECM remodeling is lysyl oxidase (Lox) that is overexpressed in different types of human cancers. Because of the high prevalence and poor survival of gastrointestinal (Gl) malignancies in this review, we discuss the association between Lox activity and the progression of $\mathrm{Gl}$ cancers. Lox proteins are a group of extracellular enzymes that catalyzed the cross-linking of collagen and elastin, so they have important roles in the control of structure and homeostasis of ECM. Abnormal activation and expression of the Lox family of proteins lead to changes in the ECM toward increased rigidity and fibrosis. Stiffness of ECM can contribute to the pathogenesis of cancers. Summary: Dysregulation of Lox expression is a factor in both fibrotic diseases and cancer. ECM stiffness by Lox overactivity creates a physical barrier against intratumoral concentration of chemotherapeutic drugs and
\end{abstract}

\begin{tabular}{ll}
\hline karger@karger.com & ( 2020 The Author(s) \\
www.karger.com/gat & Published by S. Karger AG, Basel \\
& This article is licensed under the Creative Commons Attribution- \\
NonCommercial-NoDerivatives 4.0 International License (CC BY- \\
NC-ND) (http://www.karger.com/Services/OpenAccessLicense). \\
Usage and distribution for commercial purposes as well as any dis- \\
tribution of modified material requires written permission.
\end{tabular}

facilitates cancer inflammation, angiogenesis, and metastasis. Key Message: Because of the roles of Lox in Gl cancers, development targeting Lox protein isotypes may be an appropriate strategy for treatment of $\mathrm{Gl}$ cancers and improvement in survival of patients.

(c) 2020 The Author(s)

Published by S. Karger AG, Basel

\section{Introduction}

Carcinogenesis is a complex process and is the consequence of various modifications such as extracellular matrix (ECM) remodeling [1]. ECM is a noncellular component including proteoglycans, fibronectin, and fibers such as collagen and elastin. ECM provides mechanical and structural support for cells and tissues [1]. Lysyl oxidase (Lox) is a copper-dependent enzyme that is encoded by the Lox gene [2]. Lox and Lox-like 1-4 are members of the Lox protein family [3] that are expressed in different cell types including endothelial cells, smooth muscle cells, and other cell types in various organs such as the gastrointestinal (GI) tract [4-6]. Lox catalyzes the cross-linking of collagen and elastin in the ECM through deamination of lysine and hydroxylysine residues to aldehyde, so they play an important role in control of structure, tensile

Mohammad-Hassan Arjmand

Medical Plants Research Center, Basic Health Sciences Institute Shahrekord University of Medical Sciences, Rahmatiyeh Center Shahrekord 8815764646 (Iran) arjmandmh1@gmail.com 
strength, and homeostasis of ECM that is essential in normal functioning of connective tissues and tissue remodeling $[7,8]$. Recent studies have reported that dysregulation of Lox activity leads to an increase in ECM remodeling as a result of cross-link density of collagen and elastin to develop ECM fibrosis. This disturbs the cell polarity, promotes cell proliferation, and contributes to cancer formation and progression. Lox mRNA and protein are highly expressed in GI organs such as the liver [9], GI submucosa [10], and pancreas [11] during fibrosis. Stromal cells around the tumor microenvironment also express high level of Lox that has critical roles in tumor invasion and metastasis $[12,13]$. Collagen is one of the major targets for Lox and is a major constituent of organ fibrosis and tumor stroma. The amount and distribution of collagen in the ECM are an important factor for the behavior of cancer cells including the conversion of signal transduction pathways, receptors, and transcriptional factors. In this review, we summarize the roles of Lox in GI malignancies focusing on ECM changes, angiogenesis, and inflammation associated with cancer development.

\section{Lox Roles in ECM Stiffness for Cancer Progression}

The ECM that surrounds cells is an important regulator for normal cellular and tissue function. The ECM is composed of water, fibrous proteins, minerals, and proteoglycans that are secreted by resident cells. Homeostasis of the ECM is important for biological processes such as wound healing, embryonic development, and normal organ function, and dysregulation of ECM changes the behavior of cells and tissues toward pathological conditions. Fibrotic diseases, tumorigenesis, and tumor cell metastasis are affected by ECM dysregulation [14]. Abnormal expression of Lox mRNA and protein has been reported in wide range of disorders related to ECM such as several malignancies [15]. Tumor microenvironment stiffness and fibrosis change it to a metastatic site and contribute tumor cells to colonize distant organs. Cox et al. [16] have reported that induction of fibrosis in the liver increases the ability of breast cancer cells to migrate and metastasis to the liver. In addition, stiffness of the ECM by Lox overactivity changes integrin signaling to modulate cell behavior. Integrins are an important member of adhesion molecules that provide a link between cells and ECM. Integrins are cell sensors that distribute information from outside to inside the cells; therefore, changes in the ECM are detected by integrins to regulate signaling pathways [17]. In pathological process such as malignancies, Lox through induction of collagen crosslinking leads to ECM stiffness and a change in the integrin signaling pathways that contribute tumor cell-ECM interactions to promote adhesions and cancer cell metastasis $[18,19]$. Recent studies have demonstrated that the stiffness of tumor microenvironment upregulates phosphatidylinositide 3-kinase (PI3K) signaling activity to promote tumor cell invasion and metastasis [20]. One of the major molecules affected by Lox is collagen I (Col I). Studies have showed that there is a close correlation between Lox with Col I expression during cancer development [21]. In addition, other studies have reported that Col I induces the proliferation and migration of tumor cells following the activation of integrin signaling [22]. Zhang et al. [23] have been demonstrated that Col I with upregulation of WNT/planar cell polarity signaling pathway increases the invasion of colorectal cancer cells. They found that the expression of Col I was induced in colon cancer tissues and was associated with tumor progression [23]. An increase in the integrin signaling pathways such as PI3K and Jun NH2-terminal kinase (JNK) by Col I was reported in pancreatic carcinoma [11]. Yamanari et al. [24] reported that culture of pancreatic cancer cells in Col I gels containing media induces cancer cell differentiation more than the same cells cultured in matrigel. Menke et al. [25] showed that pancreatic cancer cells stimulate the migration, proliferation, and cell morphogenetic transformation in response to Col I. Hypoxia is a master regulator for ECM stiffness. Lox induces Col I expression under hypoxic condition to make a collagen-rich ECM. Transcription factor hypoxia-inducible factor-1 $\alpha$ (HIF-1 $\alpha$ ) binds to the Lox promoter under hypoxic conditions. HIF-1 $\alpha$ induces the expression of Lox mRNA in different types of cancer $[26,27]$. Therefore, the HIF-1a/Lox/Coll pathway leads to profibrotic microenvironment to facilitate tumor cell migration and metastasis. Moreover, Lox activity is involved in the epithelial-mesenchymal transition (EMT) that is essential for cancer cell metastasis. Various studies have reported that HIF-1a stimulates the EMT in vitro and induces epithelial cell migration by upregulation of Lox $[13,28]$. Park et al. [29] have showed that positive Lox colorectal cells have more migratory potential compared with negative Lox cells. They showed that Lox promotes the EMT process and strongly declares the prometastatic role of Lox in colorectal cancer. These findings suggest important roles of Lox as a mediator of tumor microenvironment stiffness and as a modulator of fibrosis-enhanced metastatic growth and provide suggestions that Lox inhibitors may have potential to reduce cancer cell metas- 


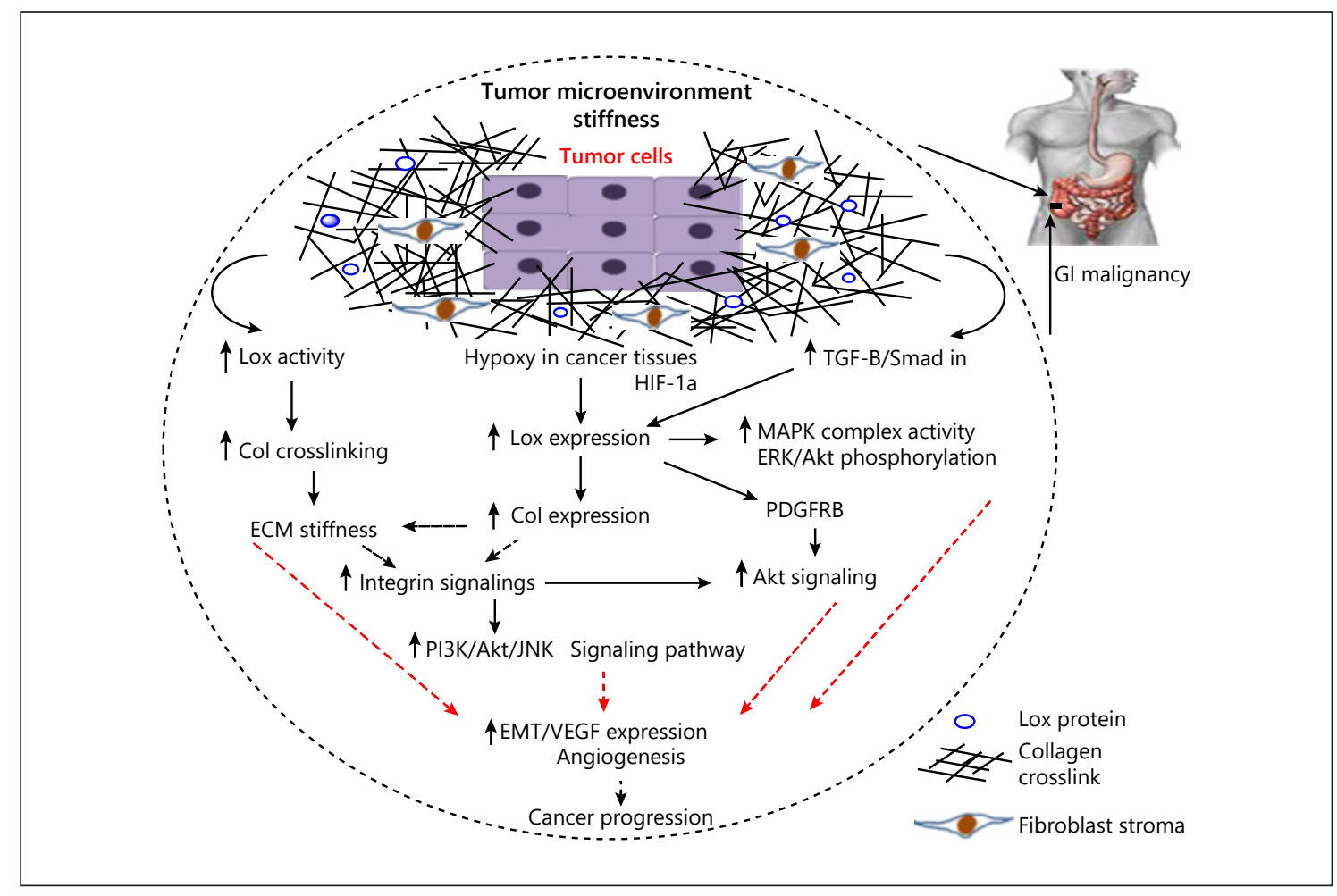

Fig. 1. Overview of the complex interplay between the roles of Lox in tumor microenvironment rigidity and cancer development. Lox with increase in collagen fiber cross-linking and ECM rigidity upregulates integrin signaling pathways to increase tumor cell invasive capacity. Moreover, Lox with activation of MAPK complex, phosphorylation of ERK and Akt, and stimulation of PDGFR $\beta$ in- duces EMT, angiogenesis, and cancer development. Also, Lox expression can be induced by HIF- $1 \alpha$ and TGF- $\beta /$ Smad which leads to cancer progression. ECM, extracellular matrix; Lox, lysyl oxidase; PDGFR $\beta$, platelet-derived growth factor receptor beta; EMT, epithelial-mesenchymal transition; TGF- $\beta$, transforming growth factor $\beta$; Col, collagen; MAPK, mitogen-activated protein kinase. tasis ability to increase patient's survival. The potential effects of Lox activity in the ECM stiffness are summarized in Figure 1.

\section{Lox Roles in Angiogenesis}

New blood vessel formation around tumors is an essential stage for tumor metastasis; angiogenesis occurs to supply oxygen and nutrients to the tumor cells [30]. Microenvironment signals including hypoxia by HIF-1 $\alpha$ induce angiogenic factors such as vascular endothelial growth factor (VEGF) and can trigger angiogenesis [31]. Lox regulates some factors involved in ECM angiogenesis. Recent studies have reported the role of Lox in vascular remodeling during angiogenesis and metastasis $[32,33]$. Lox by the activation of the mitogen-activated protein kinase (MAPK) complex and phosphorylation of Akt and ERK protein signaling stimulates the expression of VEGF $[34,35]$. Lox is also able to increase the expression of VEGF via transforming growth factor $\beta$ (TGF- $\beta$ ) signaling activity. Lox is a target for TGF- $\beta /$ Smad signaling pathways; therefore, TGF- $\beta$ upregulates the expression of VEGF through Lox [36]. TGF- $\beta$ is an important profibrotic cytokine that induces ECM stiffness in fibrotic conditions; moreover, TGF- $\beta$ signaling has been shown to promote the production of Lox and collagens. TGF- $\beta$ /Lox upregulates tumor microenvironment stiffness and angiogenesis. Zhu et al. [34] have demonstrated that TGF- $\beta$ can upregulate both Lox and VEGF in hepatocellular carcinoma (HCC) cells and TGF- $\beta /$ Lox leads to ECM stiffness by increasing the expression and crosslinking of collagens, especially Col I. The tumor microenvironment stiffness is stimulated by Col I via the integrin $\beta 1$ signaling pathway that leads to PI3K and Akt hyperphosphorylation to stimulate VEGF expression in HCC [34]. PI3K/Akt is one of the chief signaling pathways in the regulation of VEGF expression. Fang et al. 
[37] have demonstrated that Lox increases the expression and cross-linking of Col IV and simulates the angiogenic and metastatic process of HCC. There is a positive correlation between VEGF expression in tumors and tumor microenvironment rigidity; on the other hand, increased ECM stiffness via Lox/Col I facilitates angiogenesis. A recent study has reported that the Lox inhibitor $\beta$-aminoproprionitrile reduces VEGF expression and angiogenesis by suppressing the activation of MAPK complex and Akt [38]. Also, other studies have reported that Lox causes the induction of platelet-derived growth factor receptor beta (PDGFR $\beta$ ) to stimulate the expression of VEGF. Baker et al. [39] have indicated that Lox with stimulation of PDGFR $\beta$ promotes Akt signaling pathways which leads to VEGF expression at both the mRNA and protein level in vitro. In next stage, they treated the cells with inhibitors of PDGFR $\beta$ or Akt-mediated signaling or inhibitors of angiogenesis; they found that these drugs abolished the Lox-mediated increases in VEGF expression. Clinical studies have shown that targeting Lox reduced angiogenesis because Lox regulates several signaling networks. In summary, these data show that Lox, an ECM-modifying enzyme, has a key role in cancer angiogenesis in experimental and clinical studies related to GI malignancies. Potential effects of Lox activity are briefed in Figure 1.

\section{Lox and Inflammation}

Recent studies have reported that Lox activity mediates inflammation in tumor microenvironment which plays an essential role in cancer progression. Abnormality in the inflammatory responses in the ECM promotes the angiogenic and metastatic processes associated with cancer cells. Several cytokines released in tumor microenvironment by infiltrating lymphocytes, cancer-associated fibroblasts, and macrophages modulate metastatic cascade. The effects of tumor necrosis factor alpha (TNF- $\alpha$ ) as an important inflammatory cytokine have been studied in different experimental animal models, and investigations show that anti-TNF drugs have potential to reduce metastasis $[40,41]$. Also, there is a strong association between inflammation and EMT to stimulate migration and metastasis of tumor cells [42]. In addition, inflammation is able to increase angiogenesis. The level of interleukin 6 (IL-6), an important inflammatory cytokine, is correlated with VEGF level in gastric and colorectal cancer [43, 44]. Inflammatory cytokines upregulate signaling pathways involved in the expression of angiogenic mediators; for example, IL-6 with phosphorylation of signal transducer and activator of transcription 3 (STAT3) promotes the expression of angiogenic mediators such as VEGF and HIF$1 \alpha$ [45]. Dysregulation of inflammatory response induced by infiltrating lymphocytes and macrophages distributes high level of TGF- $\beta$ in tumor microenvironment that contributes proangiogenic effects [46]. Saito et al. [47] have showed a significant correlation between TGF- $\beta$ and VEGF expression in gastric malignant tissues associated with poor prognosis in patients with advanced gastric carcinoma. Various studies demonstrated that the rigidity and fibrosis of ECM related to Lox overexpression lead to an increase in inflammation to promote tumor invasion. Jeong et al. [48] have showed that the Lox expression was connected with intratumoral and peritumoral inflammation; they found that the Lox expression was positively correlated with IL-4 expression and T-cell differentiation in fibrotic breast cancer. Fibrosis is associated with inflammation; therefore, ECM rigidity by overactivation of Lox promotes inflammation that leads to cancer development. Few studies have demonstrated that Lox expression is regulated with inflammatory mediators under inflammation condition. TGF- $\beta 1$ as an inflammatory and profibrotic cytokine upregulates the mRNA and protein expression of Lox in fibroblasts. Voloshenyuk et al. [49] have indicated that TGF- $\beta$ by Smad signaling pathways stimulates the Lox expression; also, they found the MAPK complex signaling pathway and PI3K/Akt activated by TGF- $\beta$ are essential for upregulation of Lox. Interleukin $1 \beta$ (IL$1 \beta)$, another important inflammatory mediator in acute inflammation, upregulates Lox expression in skin and lung fibroblasts $[50,51]$. Moreover, TNF- $\alpha$ as a main inflammatory cytokine increases Lox expression through TGF- $\beta /$ Smad and PI3K signaling pathways [52]. The roles of Lox in cancer progression are summarized in Table 1.

\section{Clinical Studies in GI Malignancies Related to Lox Overactivity}

Various clinical studies have investigated the association between Lox expression and clinicopathogical features, progression, and prognosis of GI cancers including colorectal, esophageal, HCC, gastric, and pancreatic carcinoma. In one study, 82 samples of colorectal tumors with healthy adjacent tissues were collected. The prognosis of patients in the following year was recorded. Also, the correlation between the Lox and HIF-1a expression was determined. It was found that the expression of Lox in tumors was significantly higher compared with the ad-
36

Gastrointest Tumors 2021;8:33-40 DOI: $10.1159 / 000511244$
Farhat et al. 
Table 1. The roles of Lox in cancer progression

\begin{tabular}{ll}
\hline LCM dysregulation & $\begin{array}{l}\text { Lox overactivity in cancer leads to ECM dysregulation including ECM stiffness and fibrosis; these conditions } \\
\text { lead to change in integrin signaling pathways, increase the cross-linking of collagens, and promote tumor cell } \\
\text { invasion and metastasis }\end{array}$ \\
\hline Angiogenesis & $\begin{array}{l}\text { Most important molecular mechanisms affected by Lox which induces angiogenesis include the following: } \\
\text { promotion of the MAPK and PI3K/Akt signaling pathways to stimulate the expression of VEGF and increase } \\
\text { in the TGF- } \beta / \text { Smad signaling upregulates the expression of VEGF to induce angiogenesis in tumors site }\end{array}$ \\
\hline $\begin{array}{l}\text { Inflammation } \\
\text { tumor invasion. Also, inflammation and increase in the inflammatory cytokines around the tumor site incre- } \\
\text { ase the mRNA and protein expression of Lox. Inflammation and Lox increase each other around the tumors }\end{array}$ \\
\hline $\begin{array}{l}\text { ECM, extracellular matrix; Lox, lysyl oxidase; TGF- } \beta \text {, transforming growth factor } \beta ; \text { MAPK, mitogen-activated protein kinase; VEGF, } \\
\text { vascular endothelial growth factor. }\end{array}$ \\
\hline
\end{tabular}

jacent tissues and there was a positive correlation between HIF-1 $\alpha$ and Lox expression. Patients with high-level expression of Lox have poorer prognosis. These results show the association between Lox and colorectal cancer progression [53]. In another study, 137 patients with colorectal adenocarcinoma were selected; the association between the expression of Lox with lymph node metastasis and patient survival was evaluated. The results showed that there was a positive correlation between the levels of the expression of Lox with lymph node aggression and high rate of distant metastasis; also, there was a strong association between Lox expression in tumors with poor survival of patients [54]. Kasashima et al. [55] have reported an association between Lox expression and clinicopathogical features of gastric cancer. In 544 patients, samples of gastric malignant tissues were collected. Patients with high Lox expression had significantly lower prognosis than those without Lox expression. Also, there was positive link between the expression of Lox and distance metastasis. Peng et al. [56] have shown that the expression of Lox in 184 gastric malignant tumors was significantly different compared with peritumoral tissues. They found that the expression of Lox was higher in patients with advanced gastric cancer including distance lymph node metastasis and serosal invasion. Also, there was a positive correlation between Lox with Col IV expression and cancer progression. In addition, survival analysis indicated that patients with high-level expression of Lox had poor survival [56]. Furthermore, the association between Lox expression and lymph node metastasis with overall survival was evaluated in patients with esophageal cancer. The protein expression of Lox was higher in esophageal squamous cell carcinoma than in normal esophageal tissues; also, the number of metastatic nodes and poor survival in patients were associated with highlevel expression of Lox in esophageal malignant tissues [57]. In another study with 148 tissues of patients with HCC, the expression of Lox in tissues was investigated simultaneously with clincopathologial features and overall survival in patients. They reported that there was a positive correlation between Lox expression in tumors and size of tumor and advanced grade of HCC; in addition, Lox had close relation with VEGF expression in HCC tissues and shorter survival [34]. These studies contribute to this theory that Lox inhibitors may have strong potential to reduce cancer progression alone or in combination with chemotherapy drugs against GI malignancies.

\section{Future Perspectives of Lox Inhibitors in Cancer Therapy}

In this review, we have discussed the roles of Lox in ECM stiffness, angiogenesis, inflammation, and cancer progression. Dysregulation of Lox expression is a factor in both fibrotic diseases and cancer. ECM stiffness by Lox overactivity creates a physical barrier against intratumoral concentration of chemotherapeutic drugs. Therefore, Lox can be a molecular target for treatment of cancers. Benjamin et al. [58] have showed that enzymatic activity of Lox promotes PDAC chemoresistance in pancreatic cancer. They found that Lox activity reduces gemcitabine intratumoral dissemination; in addition, adjuvant gem- 
citabine benefit was decreased by the increase in collagen fiber organization as a result of Lox activity [58]. The first Lox2 humanized monoclonal antibody (simtuzumab) has recently been developed and has entered phase II clinical trials for pancreatic cancer. A combination of simtuzumab with chemotherapy agent gemcitabine failed to increase survival of patients compared to gemcitabine alone [59]. Also, in another randomized, double-blinded clinical trial, the effects of simtuzumab in combination with FOLFIRI were used for the treatment of metastatic KRAS mutant colorectal cancer. The combination of simtuzumab with FOLFIRI did not improve clinical outcomes of patients [60]. These results suggest that targeting only 1 member of Lox family is probably to have no clinical benefit, and further studies are needed to develop more effective drugs to inhibit Lox family activities.

\section{Conclusion}

Our review has made a concept about the Lox activity mechanisms in facilitating cancer inflammation, angiogenesis, and metastasis. Control of ECM is essential for regulating many crucial cellular processes. ECM stiffness is a key factor for cancer development contributed by Lox activity. Lox overactivity upregulates different molecular signaling pathways associated with ECM rigidity and fibrosis. Because the association between Lox and cancer development can be a molecular target for anti-cancer treatment, novel therapeutic strategies in cancers with the target of Lox inhibition open windows to decrease chemoresistance and can- cer progression and increase overall survival of patients. Drug delivery with the goal of Lox isotope inhibition or combination of monoclonal antibodies against the Lox isotypes with routine chemotherapy drugs may be effective in decreasing progression of GI malignancies. Recent studies have showed that targeting Lox isotype 1 has potential for inhibition of tumor progression and metastasis in colorectal cancer. One study in California showed that a monoclonal antibody (AB0023) against Lox isotype 2 was effective in primary or metastatic xenograft models of cancer. Therefore, based on roles of Lox in pathogenesis of cancer, inhibition of the Lox activity and development of drugs to target Lox family may have therapeutic significance for treatment of GI tumors in the clinic to improve patient's conditions, so more studies are required to confirm this conclusion.

\section{Conflict of Interest Statement}

The authors have no conflicts of interest to disclose.

\section{Funding Sources}

The authors did not receive any funding.

\section{Author Contributions}

Ahmadshah Farhat and Korosh Ashrafi interpreted data for the work; Gordon A. Ferns revised the manuscript for intellectual contents; Mohammad-Hassan Arjmand designed the work and approved the final version to be published.

\section{References}

1 Pupa SM, Ménard S, Forti S, Tagliabue E. New insights into the role of extracellular matrix during tumor onset and progression. J Cell Physiol. 2002;192(3):259-67.

2 Hämäläinen ER, Jones TA, Sheer D, Taskinen K, Pihlajaniemi T, Kivirikko KI. Molecular cloning of human lysyl oxidase and assignment of the gene to chromosome 5q23.331.2. Genomics. 1991;11(3):508-16.

3 Panchenko MV, Stetler-Stevenson WG, Trubetskoy OV, Gacheru SN, Kagan HM. Metalloproteinase activity secreted by fibrogenic cells in the processing of prolysyl oxidase. Potential role of procollagen C-proteinase. J Biol Chem. 1996 Mar 22;271(12):7113-9.

4 Sakai M, Kato H, Sano A, Tanaka N, Inose T, Kimura H, et al. Expression of lysyl oxidase is correlated with lymph node metastasis and poor prognosis in esophageal squamous cell carcinoma. Ann Surg Oncol. 2009;16(9):2494-501.
5 Zhang Q, Jin XS, Yang ZY, Wei M, Zhu XC, Wang $P$, et al. Upregulated expression of LOX is a novel independent prognostic marker of worse outcome in gastric cancer patients after curative surgery. Oncol Lett. 2013;5(3):896902.

6 Tanaka N, Yamada S, Sonohara F, Suenaga M, Hayashi M, Takami H, et al. Clinical implications of lysyl oxidase-like protein 2 expression in pancreatic cancer. Sci Rep. 2018;8(1):1-9.

7 Pinnell SR, Martin GR. The cross-linking of collagen and elastin: enzymatic conversion of lysine in peptide linkage to alpha-aminoadipic-delta-semialdehyde (allysine) by an extract from bone. Proc Natl Acad Sci U S A. 1968; 61(2):708

8 Smith-Mungo LI, Kagan HM. Lysyl oxidase: properties, regulation and multiple functions in biology. Matrix Biol. 1998;16(7):387-98.
9 Kagan HM. Lysyl oxidase: mechanism, regulation and relationship to liver fibrosis. Pathol Res Pract. 1994 Oct;190(9-10):910-9.

10 Trivedy C, Warnakulasuriya KA, Hazarey VK, Tavassoli M, Sommer P, Johnson NW. The upregulation of lysyl oxidase in oral submucous fibrosis and squamous cell carcinoma. J Oral Pathol Med. 1999 Jul;28(6):24651.

11 Shintani Y, Hollingsworth MA, Wheelock MJ, Johnson KR. Collagen I promotes metastasis in pancreatic cancer by activating c-Jun $\mathrm{NH}(2)$-terminal kinase 1 and up-regulating $\mathrm{N}$-cadherin expression. Cancer Res. 2006; 66(24):11745-53.

12 Bissell MJ, Labarge MA. Context, tissue plasticity, and cancer: are tumor stem cells also regulated by the microenvironment? Cancer Cell. 2005 Jan;7(1):17-23. 
13 Erler JT, Bennewith KL, Nicolau M, Dornhöfer N, Kong C, Le QT, et al. Lysyl oxidase is essential for hypoxia-induced metastasis. Nature. 2006 Apr 27;440(7088):1222-6.

14 Levental KR, Yu H, Kass L, Lakins JN, Egeblad $\mathrm{M}$, Erler JT, et al. Matrix crosslinking forces tumor progression by enhancing integrin signaling. Cell. 2009;139(5):891-906.

15 Payne SL, Hendrix MJ, Kirschmann DA. Paradoxical roles for lysyl oxidases in cancer: a prospect. J Cell Biochem. 2007;101(6):133854.

16 Cox TR, Bird D, Baker AM, Barker HE, Ho MW, Lang G, et al. LOX-mediated collagen crosslinking is responsible for fibrosis-enhanced metastasis. Cancer Res. 2013 Mar 15; 73(6):1721-32.

17 Horton ER, Byron A, Askari JA, Ng DHJ, Millon-Frémillon A, Robertson J, et al. Definition of a consensus integrin adhesome and its dynamics during adhesion complex assembly and disassembly. Nat Cell Biol. 2015 Dec; 17(12):1577-87.

18 Hynes RO. Integrins: bidirectional, allosteric signaling machines. Cell. 2002 Sep 20;110(6): 673-87.

19 Lawson CD, Burridge K. The on-off relationship of Rho and Rac during integrin-mediated adhesion and cell migration. Small GTPases. 2014;5:e27958.

20 Rubashkin MG, Cassereau L, Bainer R, DuFort CC, Yui Y, Ou G, et al. Force engages vinculin and promotes tumor progression by enhancing PI3K activation of phosphatidylinositol $(3,4,5)$-triphosphate. Cancer Res. 2014 Sep 1;74(17):4597-611.

21 Cox TR, Bird D, Baker AM, Barker HE, Ho MW, Lang G, et al. LOX-mediated collagen crosslinking is responsible for fibrosis-enhanced metastasis. Cancer Res. 2013;73(6): 1721-32.

22 Barkan D, El Touny LH, Michalowski AM, Smith JA, Chu I, Davis AS, et al. Metastatic growth from dormant cells induced by a colI-enriched fibrotic environment. Cancer Res. 2010 Jul 15;70(14):5706-16.

23 Zhang Z, Wang Y, Zhang J, Zhong J, Yang R. COL1A1 promotes metastasis in colorectal cancer by regulating the WNT/PCP pathway. Mol Med Rep. 2018 Apr;17(4):5037-42.

24 Yamanari H, Suganuma T, Iwamura T, Kitamura N, Taniguchi S, Setoguchi T. Extracellular matrix components regulating glandular differentiation and the formation of basal lamina of a human pancreatic cancer cell line in vitro. Exp Cell Res. 1994 Apr;211(2):17582.

25 Menke A, Philippi C, Vogelmann R, Seidel B, Lutz MP, Adler G, et al. Down-regulation of E-cadherin gene expression by collagen type I and type III in pancreatic cancer cell lines. Cancer Res. 2001;61(8):3508-17.

26 Erler JT, Giaccia AJ. Lysyl oxidase mediates hypoxic control of metastasis. Cancer Res. 2006;66(21):10238-41.
27 Ji F, Wang Y, Qiu L, Li S, Zhu J, Liang Z, et al. Hypoxia inducible factor $1 \alpha$-mediated LOX expression correlates with migration and invasion in epithelial ovarian cancer. Int J Oncol. 2013;42(5):1578-88.

28 Higgins DF, Kimura K, Bernhardt WM, Shrimanker N, Akai Y, Hohenstein B, et al. Hypoxia promotes fibrogenesis in vivo via HIF-1 stimulation of epithelial-to-mesenchymal transition. J Clin Invest. 2007 Dec;117(12): 3810-20.

29 Park PG, Jo SJ, Kim MJ, Kim HJ, Lee JH, Park $\mathrm{CK}$, et al. Role of LOXL2 in the epithelialmesenchymal transition and colorectal cancer metastasis. Oncotarget. 2017 Oct 6;8(46): 80325-35.

30 Liotta LA, Stracke ML. Tumor invasion and metastases: biochemical mechanisms. Cancer Treat Res. 1988;40:223-38.

31 Shweiki D, Neeman M, Itin A, Keshet E. Induction of vascular endothelial growth factor expression by hypoxia and by glucose deficiency in multicell spheroids: implications for tumor angiogenesis. Proc Natl Acad Sci U S A. 1995 Jan 31;92(3):768-72.

32 Orriols M, Guadall A, Galán M, Martí-Pàmies I, Varona S, Rodríguez-Calvo R, et al. Lysyl oxidase (LOX) in vascular remodelling. Insight from a new animal model. Thromb Haemost. 2014 Oct;112(4):812-24.

33 Ribeiro AL, Kaid C, Silva PBG, Cortez BA, Okamoto OK. Inhibition of lysyl oxidases impairs migration and angiogenic properties of tumor-associated pericytes. Stem Cells Int. 2017;2017:4972078.

34 Zhu J, Huang S, Wu G, Huang C, Li X, Chen $\mathrm{Z}$, et al. Lysyl oxidase is predictive of unfavorable outcomes and essential for regulation of vascular endothelial growth factor in hepatocellular carcinoma. Dig Dis Sci. 2015 Oct: 60(10):3019-31.

35 Bae WJ, Yi JK, Park J, Kang SK, Jang JH, Kim EC. Lysyl oxidase-mediated VEGF-induced differentiation and angiogenesis in human dental pulp cells. Int Endod J. 2018 Mar;51(3): $335-46$.

36 Dong Y, Xie X, Wang Z, Hu C, Zheng Q, Wang $Y$, et al. Increasing matrix stiffness upregulates vascular endothelial growth factor expression in hepatocellular carcinoma cells mediated by integrin $\beta 1$. Biochem Biophys Res Commun. 2014 Feb 14;444(3):427-32.

37 Fang M, Peng CW, Yuan JP, Zhang ZL, Pang DW, Li Y. Coevolution of the tumor microenvironment revealed by quantum dot-based multiplexed imaging of hepatocellular carcinoma. Future Oncol. 2013 Jul;9(7):1029-37.

38 Shi L, Zhang N, Liu H, Zhao L, Liu J, Wan J, et al. Lysyl oxidase inhibition via $\beta$-aminoproprionitrile hampers human umbilical vein endothelial cell angiogenesis and migration in vitro. Mol Med Rep. 2018 Apr; 17(4):5029-36.
39 Baker AM, Bird D, Welti JC, Gourlaouen M, Lang G, Murray GI, et al. Lysyl oxidase plays a critical role in endothelial cell stimulation to drive tumor angiogenesis. Cancer Res. 2013 Jan 15;73(2):583-94.

40 Orosz P, Echtenacher B, Falk W, Rüschoff J, Weber D, Männel DN. Enhancement of experimental metastasis by tumor necrosis factor. J Exp Med. 1993;177(5):1391-8.

41 Orosz P, Krüger A, Hubbe M, Rüschoff J, Von Hoegen P, Männel DN. Promotion of experimental liver metastasis by tumor necrosis factor. Int J Cancer. 1995;60(6):867-71.

42 Samatov TR, Tonevitsky AG, Schumacher U. Epithelial-mesenchymal transition: focus on metastatic cascade, alternative splicing, noncoding RNAs and modulating compounds. Mol Cancer. 2013;12(1):107.

43 Kim HK, Song KS, Park YS, Kang YH, Lee YJ, Lee KR, et al. Elevated levels of circulating platelet microparticles, VEGF, IL-6 and RANTES in patients with gastric cancer: possible role of a metastasis predictor. Eur J Cancer. 2003;39(2):184-91.

44 Eldesoky A, Shouma A, Mosaad Y, Elhawary A. Clinical relevance of serum vascular endothelial growth factor and interleukin-6 in patients with colorectal cancer. Saudi J Gastroenterol. 2011;17(3):170.

45 Boreddy SR, Sahu RP, Srivastava SK. Benzyl isothiocyanate suppresses pancreatic tumor angiogenesis and invasion by inhibiting HIF-a/VEGF/Rho-GTPases: pivotal role of STAT-3. PLoS One. 2011;6(10):e25799.

46 Levy L, Hill CS. Alterations in components of the TGF-beta superfamily signaling pathways in human cancer. Cytokine Growth Factor Rev. 2006;17(1-2):41-58.

47 Saito H, Tsujitani S, Oka S, Kondo A, Ikeguchi $\mathrm{M}$, Maeta $\mathrm{M}$, et al. The expression of transforming growth factor-betal is significantly correlated with the expression of vascular endothelial growth factor and poor prognosis of patients with advanced gastric carcinoma. Cancer. 1999;86(8):1455-62.

48 Jeong YJ, Park SH, Mun SH, Kwak SG, Lee SJ, Oh HK. Association between lysyl oxidase and fibrotic focus in relation with inflammation in breast cancer. Oncol Lett. 2018;15(2): 2431-40.

49 Voloshenyuk TG, Landesman ES, Khoutorova E, Hart AD, Gardner JD. Induction of cardiac fibroblast lysyl oxidase by TGF- $\beta 1$ requires PI3K/Akt, Smad3, and MAPK signaling. Cytokine. 2011 Jul;55(1):90-7.

50 Cenizo V, André V, Reymermier C, Sommer P, Damour O, Perrier E. LOXL as a target to increase the elastin content in adult skin: a dill extract induces the LOXL gene expression. Exp Dermatol. 2006 Aug;15(8):574-81.

51 Xie J, Wang C, Yin L, Xu C, Zhang Y, Sung KL. Interleukin-1 beta influences on lysyl oxidases and matrix metalloproteinases profile of injured anterior cruciate ligament and medial collateral ligament fibroblasts. Int Orthop. 2013 Mar;37(3):495-505. 
52 Voloshenyuk TG, Hart AD, Khoutorova E, Gardner JD. TNF- $\alpha$ increases cardiac fibroblast lysyl oxidase expression through TGF- $\beta$ and PI3Kinase signaling pathways. Biochem Biophys Res Commun. 2011 Sep 23;413(2): 370-5.

53 Shi XM, Zhao W, Yang YB, Lu BN. [Expression of LOX in colorectal cancer tissues and its relationship with progress and prognosis]. Sichuan Da Xue Xue Bao Yi Xue Ban. 2017 Jul;48(4):566-9.

54 Liu N, Cox TR, Cui W, Adell G, Holmlund B, Ping J, et al. Nuclear expression of lysyl oxidase enzyme is an independent prognostic factor in rectal cancer patients. Oncotarget. 2017 Sep 1;8(36):60015-24.
55 Kasashima $\mathrm{H}$, Yashiro M, Kinoshita H, Fukuoka T, Morisaki T, Masuda G, et al. Lysyl oxidase is associated with the epithelial-mesenchymal transition of gastric cancer cells in hypoxia. Gastric Cancer. 2016 Apr;19(2): $431-42$.

56 Peng C, Liu J, Yang G, Li Y. Lysyl oxidase activates cancer stromal cells and promotes gastric cancer progression: quantum dot-based identification of biomarkers in cancer stromal cells. Int J Nanomedicine. 2018;13:161-74.

57 Sakai M, Kato H, Sano A, Tanaka N, Inose T, Kimura $\mathrm{H}$, et al. Expression of lysyl oxidase is correlated with lymph node metastasis and poor prognosis in esophageal squamous cell carcinoma. Ann Surg Oncol. 2009 Sep;16(9): 2494-501.

58 Le Calve B, Griveau A, Vindrieux D, Marechal R, Wiel C, Svrcek M, et al. Lysyl oxidase family activity promotes resistance of pancreatic ductal adenocarcinoma to chemotherapy by limiting the intratumoral anticancer drug distribution. Oncotarget. 2016 May 31;7(22): 32100-12.
59 Benson AB, Thai Z, Hawkins MJ, Werner D, Dong $\mathrm{H}$, Lee $\mathrm{C}$, et al. A phase II randomized, double-blinded, placebo-controlled study to evaluate the efficacy and safety of simtuzumab (GS-6624) combined with gemcitabine as first-line treatment for metastatic pancreatic adenocarcinoma. J Clin Oncol. 2013;31(15_ Suppl 1):TPS4149-49.

60 Hecht JR, Benson AB 3rd, Vyushkov D, Yang Y, Bendell J, Verma U. A phase II, randomized, double-blind, placebo-controlled study of simtuzumab in combination with FOLFIRI for the second-line treatment of metastatic KRAS mutant colorectal adenocarcinoma. Oncologist. 2017 Mar;22(3):243-e23. 